\title{
A Seven Year Review of the Seroprevalence of Transfusion Transmitted Infections in a Hospital Based Blood Bank in Ibadan, Nigeria
}

\author{
Foluke Atinuke Fasola ${ }^{1, ~ *}$, Patricia Adedoyin Fadimu², Victoria Oluwabunmi Akpan ${ }^{2}$ \\ ${ }^{1}$ Department of Haematology, College of Medicine, University of Ibadan, University College Hospital, Ibadan, Nigeria \\ ${ }^{2}$ Department of Haematology, Blood Bank, University College Hospital, Ibadan, Nigeria
}

Email address:

folukefasola@yahoo.com (F. A. Fasola), fadpat@gmail.com (P. A. Fadimu), tripledee3012@gmail.com (V. O. Akpan)

*Corresponding author

\section{To cite this article:}

Foluke Atinuke Fasola, Patricia Adedoyin Fadimu, Victoria Oluwabunmi Akpan. A Seven Year Review of the Seroprevalence of Transfusion Transmitted Infections in a Hospital Based Blood Bank in Ibadan, Nigeria. Clinical Medicine Research. Vol. 6, No. 1, 2017 , pp. 1-8. doi: 10.11648/j.cmr.20170601.11

Received: January 5, 2017; Accepted: January 19, 2017; Published: February 23, 2017

\begin{abstract}
Africa has the highest prevalence of transfusion transmitted infections. The World Health Organization recommends universal and quality-controlled screening of blood donations for the major transfusion-transmissible infections (TTIs): human immunodeficiency virus (HIV), hepatitis B virus (HBV), hepatitis C virus (HCV) and syphilis. Therefore a retrospective study was conducted to assess the effect of strategies in our blood bank to improve blood safety on the seroprevalence of HIV, HCV, HBV and syphilis infections among the donors over a seven year period. Existing data in the blood bank was used to determine number of the blood donors who were infected with HIV, HCV, HBV and syphilis. The test methods used to screen the donors were identified. The trend of prevalence of the transfusion transmitted infections among the blood donors from 2009 to 2015 was also determine. A total of 41,445 blood donors were screened. Voluntary blood donors constituted $11.1 \%$ of the donor population. The overall seroprevalence rate for the TTI was $12.3 \%$. The prevalence was highest for HBV (8.5\%) followed by HIV (1.8\%), HCV (1.4\%) and least for syphilis $(0.5 \%)$ respectively. The infections showed significant inter-year variation $(\mathrm{p}<.001)$. A decreasing trend was observed for HBV among the blood donors while increase in prevalence of HIV, HCV and syphilis was observed from 2012 to 2014 and decreased in 2015. The prevalence of syphilis has risen from $0 \%$ in 2009 to $0.9 \%$ in 2015 . The seroprevalence for TTI is high but is less compared to report from a previous study in same blood bank. The increasing infection rate for syphilis and sporadic surges in rates for HIV, HCV may suggest that the selection criteria is not effectively eliminating blood donors with risky lifestyle. There is need to educate the blood donors on avoiding risky lifestyle while also intensifying voluntary blood donor motivation strategy and increase community surveillance of the infections.
\end{abstract}

Keywords: Hepatitis B Virus, Hepatitis C Virus, Human Immunodeficiency Virus, Syphilis

\section{Introduction}

A transfusion transmissible infection (TTI) could be a virus, bacteria, parasite, or other potential pathogen that can be transmitted through blood transfusion into a recipient. The range of infectious agents known to be transmitted through blood transfusion are numerous. In vitro screening for all the organisms is not practicable. Transfusion transmitted infection is a major challenge to the transfusion services all over the world. World health organization recommends a mandatory screening of all blood donors and units for human immunodeficiency virus (HIV), hepatitis $\mathrm{C}$ virus (HCV), hepatitis B virus (HBV) and syphilis infections. The problem of TTI is directly proportionate to the prevalence of the infection in the blood donor community. The magnitude of the problem varies from country to country.

Standard procedures ensure that no donated blood is released for issue until all the required laboratory tests declare the blood negative for TTI. Donor screening can be broadly divided into two main categories: mandatory and 
discretionary. The mandatory tests include antigen/antibody $(\mathrm{Ag} / \mathrm{Ab})$ for human immunodeficiency viruses (HIV) $1+2$, anti-HCV for hepatitis $\mathrm{C}$ virus $(\mathrm{HCV})$ for $\mathrm{HCV}$, hepatitis $\mathrm{B}$ surface antigen (HBsAg) for hepatitis B virus (HBV), antitreponemal antibody for syphilis. The inclusion of antiHTLV I/II is considered good practice but not necessarily mandatory. Genomic screening for $\mathrm{HIV}, \mathrm{HCV}$ and $\mathrm{HBV}$ is not mandatory but can be performed on the original donor sample as an alternative to quarantine and follow-up serological testing.

In developed countries, combination of serological tests and viral detection are carried out to screen blood for HBV infection. HBV infection in donations varies between 3.6 and 8.5 per million in the USA and Canada and $0.91-13.9$ per million in Europe. For the detection of $\mathrm{HCV}$, direct detection of virus is carried out with a yield 0.93 per million in Europe and 3.92 per million donations in North America [1]. The risk of transmitting HIV through blood transfusion in the developed country is 0.14 to 1.1 per million donations ${ }^{1}$. Report from Burkino Faso, a country in Africa gave a seroprevalence of $13.4 \%$ and $6.3 \%$ for HBV and HCV respectively [2].

In Nigeria, hepatitis $\mathrm{B}$ virus (HBV), hepatitis $\mathrm{C}$ virus (HCV), and human immunodeficiency virus (HIV) infections are important causes of concern. Hepatitis B and C infections are prevalent in Nigeria with a carrier rate of about $10-20 \%$ and $0.5-6 \%$, respectively among blood donors [3, 4, 5]. Exceptionally high seroprevalence has been reported in Benin - city Nigeria ${ }^{6}$ Post transfusion hepatitis has been reported to be as high as $12.5 \%$ in Nigeria, though this was before the advent of screening for hepatitis $\mathrm{C}$ virus (HCV) [7]. Over the last decade many blood banks in the country have included screening for hepatitis $\mathrm{C}$. The seroprevalence rate for HIV among blood donors is different in various parts of the country. It ranges from 1.0 to $5.8 \%[4,8,10]$. A previous study showed fluctuating high seroprevalence rates among our blood donors ${ }^{11}$. In one study from Ibadan, a few infected blood units was reported to have escaped the serological screening process [12]. This further raises concern to frequently monitor blood safety. During the study that showed fluctuating high seroprevalence rates, pre-donation screening for $\mathrm{HbsAg}$ and anti $-\mathrm{HIV}$ rapid test were performed for all the prospective blood donors. The blood donors who were reactive were permanently deferred while the non-reactive blood donors were bled and the donated blood units were further subjected to automated ELIZA screening for HIV and HCV only. During that period, our blood bank was not screening for Treponema pallidum (T. pallidum), the causative agent of syphilis. Syphilis was reported to be as high as $2.6 \%$ among blood donors in a study from Nigeria [13].

Over the years, new test methods have emerged to improve the detection levels of the transfusion transmitted microbial agent. In the European Union, two selection strategies are employed to determine the qualification of newly-registered blood donors: a single-visit selection called the standard selection procedure (SSP), and a two-stage selection named pre-donation and donation screening (PDS) [14].

Monitoring the trends in the incidence of transmissible infectious agents in the blood donations has motivated the introduction of new screening techniques to improved early detection of infected individuals. In 2008, the screening algorithm to improve blood safety in our blood bank was changed to include predonation HCV and HIV screening in addition to the predonation $\mathrm{HbsAg}$ test being carried out in the previous years and donated blood units are again screened for HIV, HCV, HBV and T. pallidum. This study was carried out to determine the seroprevalence rate of HIV, $\mathrm{HBV}, \mathrm{HCV}$ and T. pallidum infection among blood donors during the last seven [7] years and also determine the value of the new screening algorithm (double test algorithm) to offer opportunity to improve blood safety.

\section{Materials and Method}

A retrospective study on existing data of all blood donors in our hospital blood bank from January to December over seven years was conducted. This included all donors aged between 18 and 64 years who intended to donate and eventually donated blood in the years 2009, 2010, 2011, 2012, 2013, 2014, and 2015. The blood bank is situated in a tertiary center that has 850 beds. The blood bank is involved in blood collection, storage, screening for TTI, fractionation of blood into fresh frozen plasma, cryoprecipitate, and platelet concentrate and issue to patients. For the purpose of this study, the definition of a prospective donor is a donor who states his/her wish to give blood and undergoes the selection criteria. The algorithm of blood donation include screening of all prospective blood donors with questions on health status and lifestyle and copper sulphate test (CuSO4) to rule out anaemia. Before a donor was allowed to donate blood, rapid tests to screen for anti-HIV 1 and 2, anti- HCV and HBsAg were performed to detect HIV, HCV and HBV respectively, after a pretest counselling on the infections. Two rapid tests were performed for HIV while one each was carried out for HCV and HBV. During the pretest counselling blood donors were given the opportunity to self -defer. Post test counselling was carried out after the rapid tests. Blood donors who were negative for the viruses were allowed to donate. The donated blood units were quarantined until results of the conventional semi-automated Enzyme linked immunosorbent assay (ELISA) to detect HIV, HCV, HBV and syphilis were available.

The rapid tests used to test for HIV were Determine and Unigold. Alere Determine (Alere Medical Co. Ltd, Japan) is an immunochromatographic test for the qualitative detection of antibodies to HIV-1 and HIV-2. It has a $97.96 \%$ specificity and $100 \%$ sensitivity while Unigold (by Trinity Biotech Plc, Ireland) is a single reagent assay for the detection of antibodies to HIV-1 and 2 in serum, plasma or whole blood with $99.7 \%$ specificity and $100 \%$ sensitivity. The rapid tests used for HCV and HBV were Rapid Test Strip respectively from First view Lab ACON (ACON Laboratories, Inc, San Diego, USA), rapid immunoassay for the detection of antibodies to $\mathrm{HCV}$ and HBsAg in whole blood, serum or plasma. It uses visual interpretation of colour 
development. The sensitivity of the tests were $99.8 \%$ and specificity 99.9 to $100 \%$.

The post donation screening of the blood units used semiautomated conventional ELISA Tests. The kit used for HIV screening was Genscreen ultra HIV Ag-Ab (Bio-Rad, Raymond Poincare 92430, Marnes Coaquettes, France).It is an enzyme immunoassay for the detection of antibodies to HIV 1 and 2 HIV. It detects p24 antigen and antibodies to HIV-1 (groups $\mathrm{M}$ and $\mathrm{O}$ ) and HIV-2 in humans serum or plasma. Monolisa HBs Ag Ultra (Bio-Rad, France) was used in the detection of HBSAg to identify donors who have Hepatitis B virus. The procedure is a qualitative one-step enzyme immunoassay based on the principle of "sandwich" type using monoclonal antibodies and polyclonal antibodies selected for their ability to bind themselves to the various subtypes of HBsAg now recognized by the WHO and the most part of variant HBV strains. HCV Ab version 4.0 Enzyme immunoassay (DIA.PRO Diagnostic Bioprobes Srl Via G. Carducci n0 2720099 Sesto San Giovanni Milano, Italy) was used for the detection of HCV antibodies (IgG and IgM are detected). The microplates used for the immunoassay were coated with $\mathrm{HCV}$-specific antigens derived from "core" and "ns" regions encoding for conservative and immunodominant antigenic determinants (Core peptide, recombinant NS4 and NS5 peptides). The Enzyme Immunoassay (ELISA) used for syphilis test was Syphilis Ab version Ultra. It uses Treponema pallidum synthetic antigens (p15, p17 and p47) for the determination of antibodies (IgG, IgM and IgA) to Treponema Pallidum The test kit has a diagnostic sensitivity and specificity of $100 \%$ respectively. Blood units found to be reactive to the tests for identifying any of TTIs were assumed positive for the respective viruses and discarded while the non-reactive were assumed to be seronegative blood units which are safe to be released for blood transfusion.

\section{Data Analysis}

Data were cleaned and prevalence generated with Microsoft Excel for all the TTIs as the number of donors who were positive per 100 donations. The rates were computed yearly from 2009 to 2015 . The $95 \%$ confidence interval and chi-square for trend was computed using WINPEPI (PEPIfor-Windows): computer programs for epidemiologists. Data was presented using tables and figure.

\section{Results}

A retrospective analysis covering the period between January 2009 and December 2015, showed that 42,729 prospective allogeneic and 64 autologous blood donors were attended to. Three percent of the blood donors failed the $\mathrm{CuSO} 4$ test used to assessment for anaemia. A total of 41,445 who passed the $\mathrm{CuSO} 4$ test were screened with rapid tests for HIV, HCV and HBV.

Table 1. Yearly distribution of voluntary blood donations and transfusion transmitted infections from 2009 to 2015.

\begin{tabular}{|c|c|c|c|c|c|}
\hline \multirow[b]{2}{*}{ Years } & \multirow{2}{*}{$\begin{array}{l}\text { Total No of blood } \\
\text { Donors }\end{array}$} & \multicolumn{2}{|l|}{ Voluntary blood donors } & \multicolumn{2}{|l|}{ Blood donors with TTI } \\
\hline & & Voluntary donors n(\%) & $\begin{array}{l}\text { 95\% Confidence Interval } \\
\text { (Lower-Upper) }\end{array}$ & $\begin{array}{l}\text { Blood donors with TTI } \\
\text { n (\%) }\end{array}$ & $\begin{array}{l}\text { 95\% Confidence Interval } \\
\text { (Lower-Upper) }\end{array}$ \\
\hline 2009 & 5355 & $490(8.1)$ & $7.4-8.8$ & $617(11.5)$ & $10.7-12.4$ \\
\hline 2010 & 8161 & $809(8.6)$ & $8.1-9.2$ & $1,183(14.5)$ & $13.8-15.3$ \\
\hline 2011 & 7887 & $986(12.5)$ & $11.8-13.3$ & $718(9.1)$ & $8.5-9.8$ \\
\hline 2012 & 7087 & $751(10.6)$ & $9.9-11.3$ & $808(11.4)$ & $10.7-12.2$ \\
\hline 2013 & 5018 & $1,009(20.1)$ & $19.0-21.2$ & $683(13.6)$ & $12.7-14.6$ \\
\hline 2014 & 4204 & $561(13.3)$ & $12.3-14.6$ & $646(15.4)$ & $14.3-16.5$ \\
\hline 2015 & 3733 & $199(5.3)$ & $4.6-6.1$ & 445 (11.9) & $10.9-13.0$ \\
\hline Total & 41,445 & $4,805(11.1)$ & $10.8-11.4$ & $5,100(12.3)$ & $12.0-12.6$ \\
\hline
\end{tabular}

Table 1 displays the frequency of recruitment of voluntary donors during the 7 year- period in comparison to the total blood donors for each year. Voluntary blood donors constituted $11.1 \%$ of the total donor population. The voluntary donors were students, hospital workers, walk - in donors, religious organizations and donor drive to companies and educational institutions. Replacement blood donors constituted $88.9 \%$. The voluntary blood donor population vary from year to year. There was a gradual increase in the number of voluntary blood donors from 2009 to 2013 without a proportionate decrease the number of blood donors who were positive for TTIs. Of the 41,445 blood donors screened, 5,100 (12.3\%) donors were positive for TTIs. A surge in the prevalence rates was observed in 2010 and 2014

Table 2. Pre-donation and post donation test results for transfusion transmitted infections from 2009 to 2015.

\begin{tabular}{|c|c|c|c|c|}
\hline Year & $\begin{array}{l}\text { Total No. of } \\
\text { blood Donors }\end{array}$ & $\begin{array}{l}\text { Donors positive with } \\
\text { pre-donation n (\%) }\end{array}$ & $\begin{array}{l}\text { Total No. of blood units screened by } \\
\text { ELISA }\end{array}$ & $\begin{array}{l}\text { No. of blood Units positive by } \\
\text { ELISA n (\%) }\end{array}$ \\
\hline 2009 & 5355 & $472(8.8)$ & 4883 & $145(3.0)$ \\
\hline 2010 & 8161 & $946(11.6)$ & 7215 & $237(3.3)$ \\
\hline 2011 & 7887 & $539(6.8)$ & 7348 & $179(2.4)$ \\
\hline 2012 & 7087 & $647(9.1)$ & 6440 & $161(2.5)$ \\
\hline 2013 & 5018 & $519(10.3)$ & 4499 & $164(3.7)$ \\
\hline 2014 & 4204 & $362(8.6)$ & 3842 & $284(7.4)$ \\
\hline 2015 & 3733 & $153(4.1)$ & 3580 & $292(8.2)$ \\
\hline Total & 41,445 & $3,638(8.8 \%)$ & 37,807 & $1,462(3.9)$ \\
\hline
\end{tabular}


Table 2 shows that of the 41,445 who were accepted as blood donors $3,638(8.8 \%)$ blood donors were positive for either of the viruses therefore 37,807 donors donated blood. Of the blood units donated, $3.9 \%$ were positive to either HIV, $\mathrm{HCV}$, HBV, or syphilis using the automated ELISA technique. There was a gradual decrease in the number of blood donors from 8161 in 2010 to 3733 in 2015 and a steady increase in the number of blood donors detected with the post donation test from 2011 to 2015 . The year 2015 had the least number of voluntary donors. The number of blood donors positive for TTI during same period using the postdonation (ELISA) test was twice the number detected during the predonation (rapid) test (Table $1 \& 2$ ). The total positivity for TTI in the pre- donations test using the rapid kit was $8.8 \%$ which constitute $71.3 \%$ of the infected blood donors. Until 2014, most of the infected donors were identified during the pre-donation test while there was no striking observed difference in predonation and post donations test results in 2014 and 2015.

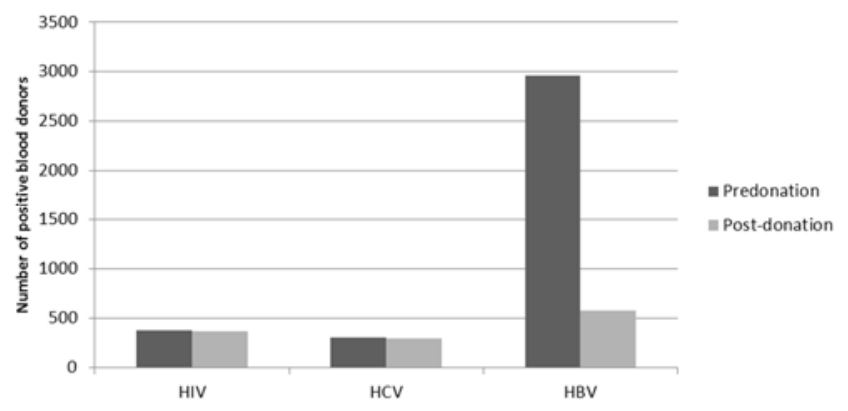

Figure 1. Detection frequency of HIV, HCV and HBV with predonation and postdonation screening test.

Of the $3540 \mathrm{HBV}$ positive blood donors only 578 (16.3\%) were detected in the post- donation tests while $49.3 \%$ and $49.4 \%$ of blood infected with HIV and HCV respectively were identified during the ELISA post donation test. (Figure $1)$.

Table 3. Year-wise seroprevalence of HIV, HCV, HBV and syphilis from 2009 to 2015.

\begin{tabular}{|c|c|c|c|c|c|c|}
\hline Year & Total No of Donors & HIV n (\%) & HCV n (\%) & HBV n (\%) & Syphilis n (\%) & Total with TTI n (\%) \\
\hline 2009 & 5355 & $98(1.8)$ & $23(0.6)$ & $496(9.3)$ & $0(0)$ & $617(11.5)$ \\
\hline 2010 & 8161 & $106(1.3)$ & $32(0.4)$ & $987(12.1)$ & $58(0.7)$ & $1,183(14.5)$ \\
\hline 2011 & 7887 & $135(1.7)$ & $136(1.7)$ & $417(5.3)$ & $30(0.4)$ & $718(9.1)$ \\
\hline 2013 & 5018 & $104(2.1)$ & $90(1.8)$ & $470(9.4)$ & $19(0.4)$ & $683(13.6)$ \\
\hline 2014 & 4204 & $114(2.7)$ & $151(3.6)$ & $324(7.7)$ & $57(1.4)$ & $646(15.4)$ \\
\hline 2015 & 3733 & $92(2.5)$ & $93(2.5)$ & $227(6.1)$ & $33(0.9)$ & 445 (11.9) \\
\hline $\mathrm{p}$-value & ND & $<0.001$ & $<0.001$ & $<0.001$ & $<0.001$ & $<0.001$ \\
\hline
\end{tabular}

Table 3: The overall seroprevalence rate for the TTI was $12.3 \%$. Hepatitis B virus had the highest prevalence $(8.5 \%)$ followed by HIV (1.8\%), HCV (1.4\%) and the least prevalent was syphilis $(0.5 \%)$. The infections showed significant interyear variation $(p<.001)$. The highest seroprevalence for TTIs was in 2014 during which highest seroprevalence was observed for each infection except HBV. None of the blood donors had syphilis in 2009. The highest prevalence for syphilis was in 2014 with 57 (1.4\%) of the donor population $(n=4204)$ who tested positive and dropped in 2015 to $0.9 \%$.

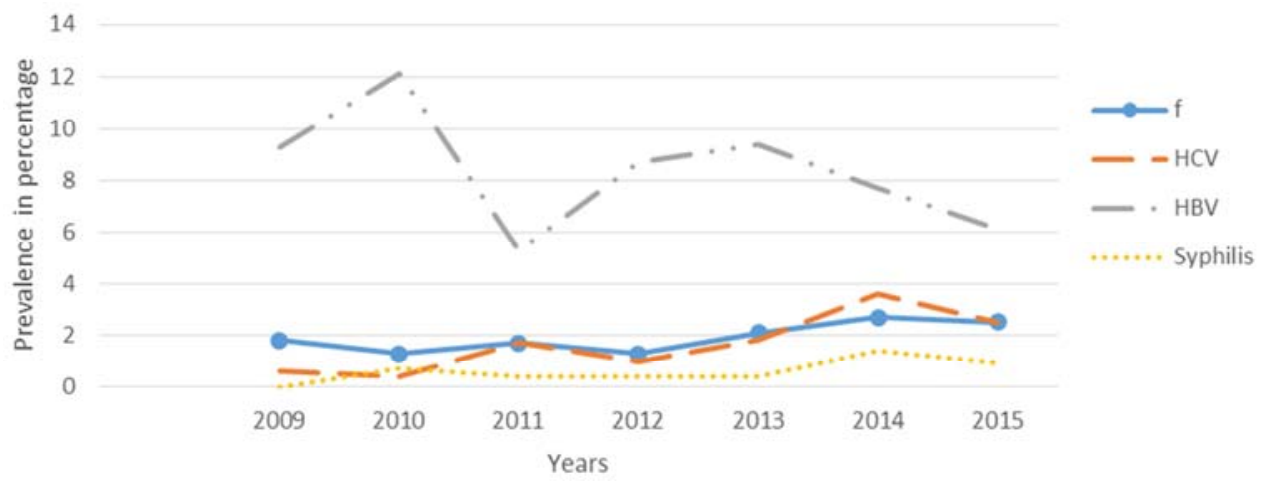

Figure 2. Trend of Seroprevalence of transfusion transmitted infection among blood donors from 2009 to 2015.

The prevalence of HBV fluctuated significantly over the 7 year period but with a declining trend (Figure 2) while the trend of infection rates for $\mathrm{HIV}, \mathrm{HCV}$ and syphilis were almost similar but opposite to that of HBV (figure 2). The fluctuation of the rates observed for HIV and HCV among the blood donors were less than $2 \%$ during the study period until 2012 for HIV and 2013 for HCV when a surge to $2.7 \%$ and $3.6 \%$ respectively in 2014 was observed. Similar to HIV and $\mathrm{HCV}$, the upsurge in seroprevalence for syphilis was in 2014.

\section{Discussion}

The overall prevalence of the TTI observed in this study is 
higher than the reported rate in a study carried out in a tertiary hospital blood bank in the same region [13]. Comparison of prevalence rates within Nigeria is flawed by the different blood donation algorithm and test methods used. The reported rate from the study on blood donors in Ife was based on rapid test. When the $8.8 \%$ obtained using rapid kit (predonation screening) tests, similar test methods were considered, the prevalence is comparable. The higher prevalence in our study may due to a better detection rate. Additional $3.9 \%$ of the infected blood units were detected by a second screening method that shortened the window period detection time and increasing the range of strains for the organisms. The similar total TTI rate but different predonation and post donation test results obtained in 2010 and 2014 underscores the importance of test methods in determining infection rates. Higher prevalence rate was obtained in a study from Ilorin, Nigeria using the predonation tests [9]. The sensitivity of rapid screening test has been reported to be suboptimal therefore the need for second ELISA screening for all donated blood units to improve blood safety [15-16]. The overall prevalence for the TTIs over the 7 years is higher that reported from a study carried out over a 4 year period during same time in Ethiopia but lower than another study carried out in same town in Ethiopia over 5 years with larger population [17, 18] Higher rates have been reported from Mozambique and Ghana [19, 20] while lower seroprevalence rate has been reported from Turkey where unlike aforementioned countries had a replacement blood donor of less than 30\% [21]. Studies outside African consistently reported less overall seroprevalence irrespective of the duration of the studies [22, $23]$ the infections showed significant inter-year variation.

The detection of a high number of infected blood units during the post- donation ELISA screening is instructive. It suggests that a significant number of TTI positive blood units might have been released to patients when only rapid predonation tests were carried out. The prevalence rate from studies carried out using rapid kit are likely to under-report the true seroprevalence.

In developed countries, HBV infection in donations varies from 1 in 300,000 the USA and 1 in 68, 000 in New Zealand to less than 1 in 2.8 million in the United Kingdom which is significantly less than what is obtained in this study [24]. However similarly to these countries Hepatitis B virus has the highest seroprevalence among the donors. There is marked reduction in the infection rate of the donors when compared with the previous study in same blood bank [11]. This suggests that there has been an improvement in the efforts made to reduce the number of infected donors in the donor population. The incorporation of HBV vaccination in the childhood immunization schedule in the last 15 years and enlightenment on the need for HBV vaccination might have contributed to reduction in the number of infected people in the general population which is being reflected in the donor population. The decline in HBV infection in the blood donor is consistent with the observation in the study at Ile- Ife, Nigeria and India $[13,22]$. However, this is in contrast to the study on Chinese donor population which showed an increasing infection rate [23] and non- directional fluctuation in a six year study from Turkey [21].

An overall seroprevalence of $1.8 \%$ for HIV infection among the blood donors is less than $3.4 \%$ recorded for the current National seroprevalence and $7.6 \%$ for a previous study in the same blood bank $[11,25]$. The blood donor HIV rate of $1.3 \%$ in 2010 was also less than $4.1 \%$ of the general population [25]. These rates are within the estimated values ranging between $1.0 \%$ and $6 \%$ reported from other regions of the country for blood donors [4, 5, 9-10]. Marked differences in the prevalence among regions in Nigeria is due to cultural differences, varying level of education, religion, differing socio-economic structure. The socio-cultural and religious practices implicated in the risk of HIV transmission include multiple and concurrent sex partners, child birth handled by unskilled birth attendant outside health facilities, use of instruments for female genital mutilation, traditional markings and tatoo. A reduction in these practices through aggressive campaign and pretest counselling for blood donors to allow them to self-defer might have contributed to the reduction. The reduction observed compared to previous report from same blood bank is encouraging except for a swinging rising in seroprevalence which peaked in 2014. This finding is in contrast to the declining infection rate observed in another study in Nigeria, Ghana, Iran [19, 26, 27]. Surprisingly, the period of rise occurred at the time more infections were detected with post donation tests compared to the predonation tests. The presence of the $13-20 \%$ voluntary blood donors during the period did not translate to decrease in the trend of the seroprevelance. The inability to determine the prevalence rate of this virus in the voluntary blood donors is a limitation of this retrospective study. Blood units obtained from voluntary blood donors are not separated from that obtained from replacement blood donors. It is important to know the motive of some of the voluntary blood donors. The information on this is not available in our records. Viral testing may be a donation incentives in a way as many firsttime donors use donation as a means to access HIV testing [28]. A study from Ghana examined transfusion risk for HIV and $\mathrm{HBV}$; the prevalence of anti - HIV and hepatitis B surface antigen in first-time volunteer vs replacement was comparable [29]. The lack of difference in TTI prevalence between voluntary non remunerated and replacement blood donors has also been shown in Brazil and Mexicos [30, 31]. Despite this observation, there is no doubt that voluntary blood donation will provide safe blood for patients. A high percentage of voluntary blood donations may be required to significantly reduce TTI in a population with high seroprevalence rate. Significant fluctuation in the voluntary donor population will suggest a fluctuating donor motivation strategies. Significant inter-professional politics and rivalry caused disruption in the health services between the years 2013 and 2015. This might account for the fluctuation in voluntary blood donation and rising trend of HIV, HCV and syphilis among the blood donors. The inability of any of the professional groups who was on strike to perform their role 
efficiently might have compromised standards and gave room for infected people to present themselves for blood donation. The same reason might explain the drop in total blood donors. An increasing trend has also been observed in other studies from china and Poland [23, 32] and Germany [33]. The rise might also suggests a fatigue in activities and programmes to stem down the spread of HIV. The increase might also suggest a rise in the number of new infections in the general population.

Studies on HCV prevalence in Sub Saharan African showed that blood donors consistently had lower prevalence $(1.9 \%)$ than the general population prevalence [34]. A prevalence of 0.8 to $6.0 \%$ has been reported among blood donors in Nigeria [4, 5, 8, 9]. A prevalence of $4.4 \%$ was reported from a neighbouring country, Ghana and $1.8 \%$ for Libya and $0.11 \%$ for California, USA [20, 35, 36]. A prevalence rate of $4.14 \%$ has been reported for Western Africa where Nigeria falls [34]. Trends of infection among the blood donors for HCV and HIV infection showed a similar pattern of moderate fluctuation. A shared route of transmission of both viruses may account for this. The inability to identify patients with dual or multiple infection is a limitation in this study. Prevalence of anti-HCV showed declining trend in Korea and Germany but has been stable in the last 20 years in Poland [32, 33, 35]. Seroprevalence of $\mathrm{HCV}$ and HIV differ over time among different categories of blood donors as declining trend was observed among first time donors while prevalence remain stable among repeat blood donors $[36,37,38]$. A seroprevalence of 0.6 and $0.4 \%$ in 2009 and 2010 which peaked to $3.6 \%$ in 2014 is alarming and should be viewed seriously. Blood donors are healthier cohort of any community and mirror the seroprevalence in the general population. The increasing trend may be a window to emerging risky behaviour and changing lifestyle. Since early identification of an epidemic is an opportunity to plan and effect intervention measure, a community based study may be relevant to unravel the increase.

The overall seroprevalence for syphilis in this study is lower than $2.1 \%$ in Burkina Faso but higher than 0.1 to $0.5 \%$ in Ethiopia [2, 17, 18, 41]. A prevalence of 0 to $8 \%$ has been reported for Nigeria [4, 14, 39, 40]. The increase in the percentage of blood donors with syphilis infection from $0 \%$ in 2009 to $1.4 \%$ in 2014 is an undesirable development. Hopefully the decline to $0.9 \%$ the following year will be a sustained downward trend in infection rate of the blood donors. The pattern of trend is in contrast to the decrease followed by a stable prevalence rate observed among Iranian blood donors [42]. Increasing trend for syphilis infection has been reported in blood donors in Pakistan [43]. The increase has been attributed to unsafe sexual practice and decline in the use of protective measures. Testing of blood donors for syphilis is used as a surrogate measure of high risk behavior in some developed countries [44]. The poor survival of Treponema pallidum, the causative agent of syphilis in refrigerator has been exploited by some blood bank as an excuse to absolve themselves of the responsibility of screening of donated blood or blood donors. This practice is unacceptable because seroconversion of blood recipients who received blood $\leq 4$ days has been reported [45]. In blood banks with inadequate blood and high demand, oftentimes blood are released for transfusion before these days required to kill the spirochete. Due to the aforementioned and the high prevalence observed in the later years of the study, transfusion services should screen for syphilis to reduce the incidence of transfusion acquired syphilis. This is further supported by a study from Ghana that observed recent infection of syphilis in $3.5 \%$ and $4.5 \%$ of the blood donors and blood recipients respectively [45].

\section{Conclusion}

Significant differences in prevalence of all the infections occur during the years under study. Reduction in seroprevalence of $\mathrm{HIV}, \mathrm{HCV}$, and $\mathrm{HBV}$ compared to previous study in the same center suggests an improvement in donor donor selection strategy. However, blood donor motivation strategies should be intensified to increase voluntary blood donation and reduce the number of blood donors likely to donate during the window period of the infections.

\section{References}

[1] Bihl F, Castelli D, Marincola F, et al (2007). Transfusiontransmitted infections. J Transl Med 5: 25 doi: 10.1186/14795876-5-25.

[2] Nagalo B. M, Bisseye C, Sanou M, et al (2012). Seroprevalence and incidence of transfusion-transmitted infectious diseases among blood donors from regional blood transfusion centres in Burkina Faso, West Africa. Trop Med Int Health 17 (2):247-53.

[3] Fasola F. A, Kotila T. R, Akinyemi J. O (2008). Trends in Transfusion-Transmitted Viral Infections in Ibadan, Nigeria. Intervirology; 51: 427-31.

[4] Motayo B. O, Faneye A. O, Udo U. A, et al (2015). Seroprevalence of transfusion transmissible infections (TTI), in first time blood donors in Abeokuta, Nigeria. African Health Sciences; 15 (1): 19-24.

[5] Buseri F. I, Muhibi M. A, Jeremiah Z. A (2009). Seroepidemiology of transfusion-transmissible infectious diseases among blood donors in Osogbo, south-west Nigeria. Blood Transfus; 7: 293-9.

[6] Dirisu J. O, Alli T. O, Adegoke A. O, et al (2011). A Survey of prevalence of serum antibodies to human immunodeficiency deficiency virus (HIV), hepatitis B virus (HBV) and hepatitis $\mathrm{C}$ virus (HCV) among blood donors. $\mathrm{N}$ Am J Med Sci.; 3 (1): 35-8.

[7] Fasola F. A, Otegbayo J. A (2002). Post Transfusion Viral Hepatitis in Sickle Cell Anaemia: Retrospective-Prospective Analysis. Journal of Clinical Practices; 5 (1): 16 - 19.

[8] Amiwero C, Prescott R. J, Okuku A. G, et al (2013). Seroprevalence transfusion transmissible infections in blood donors attending the Federal Medical center, Bida. Int. J Mod Biol Res.; 1: 1-7. 
[9] Shittu A. O, Olawumi H. O, Adewuyi J. O (2014). Predonation screening of blood for transfusion transmissible infections: the gains and the pains-experience at a resource limited blood bank. Ghana Medical Journal; 48 (3): 158-62.

[10] Osaro E, Mohammed N, Zama I, et al (2014). Prevalence of p24 antigen among a cohort of HIV antibody negative blood donors in Sokoto, North Western Nigeria - the question of safety of blood transfusion in Nigeria. Pan Afr Med J. 18: 174 doi:10.11604/pamj..18.174.3449.

[11] Fasola F. A, Kotila T. R, Akinyemi J. O (2008). Trends in Transfusion transmitted infections from 2001 to 2006 in Ibadan, Nigeria. Intervirol; 51: 427-431.

[12] Odaibo G. N, Taiwo A, Aken'Ova Y. A, et al (2008). Detection of HIV antigen and cDNA among antibodynegative blood samples in Nigeria. Trans R Soc Trop Med Hyg. 102 (3): 284-7.

[13] Salawu L, Bolarinwa R. A, Adegunloye A. B, et al (2010). HBsAg, anti-HCV, anti-HIV and VDRL in blood donors: Prevalence and trends in the last three and a half years in a tertiary health care facility in Ile-Ife, Nigeria. Int. J. Med. Med. Sci.; 2 (11): 335 - 41.

[14] Lieshout-Krikke R. W, Domanovic D, De Kort W, et al (2016). Selection strategies for newly registered blood donors in European countries. Blood Transfus.; 27: 1-7.

[15] Pruett C. R, Vermeulen M, Zacharias P, et al (2015). The use of rapid diagnostic tests for transfusion infectious screening in Africa: a literature review. Transfus Med Rev.; 29 (1): 35-44.

[16] Orkuma J. A, Egesie J. O, Banwat E. B, et al (2014). HIV screening in blood donors: rapid diagnostic test versus enhanced ELISA. Niger J Med.; 23 (3): 192-200.

[17] Mohammed Y, Bekele A (2016). Seroprevalence of transfusion transmitted infection among blood donors at Jijiga blood bank, Eastern Ethiopia: retrospective 4 years study. BMC Res Notes.; 9: 129- 35.

[18] Abate M, Wolde T (2016). Seroprevalence of Human Immunodeficiency Virus, Hepatitis B Virus, Hepatitis C Virus, and Syphilis among Blood Donors at Jigjiga Blood Bank, Eastern Ethiopia. Ethiop J Health Sci.; 26 (2): 153-60.

[19] Stokx J, Gillet P, De Weggheleire A, et al (2011). Seroprevalence of transfusion-transmissible infections and evaluation of the pre-donation screening performance at the Provincial Hospital of Tete, Mozambique. BMC Infectious Diseases; 11: 1-8.

[20] Walana W, Ahiaba S, Hokey P, et al (2014). Seroprevalence of HIV, HBV and HCV among Blood Donors in the Kintampo Municipal Hospital, Ghana. British Microbiology Research Journal 4 (12): 1491-499.

[21] Uzun B, Gungor S, Demirci M (2013). Seroprevalence of transfusion transmissible infections among blood donors in western part of Turkey: a six-year study. Transfus Apher Science. 49 (3): 511-15.

[22] Sharma DC, Rai S, Bharat S, et al (2014). Transfusion transmissible infections among blood donors at the blood bank of Medical College of Gwalior: A 5 year study. IBRR 2 (5): 235-46.

[23] Yang S, Jiao D, Liu C, et al (2016). Seroprevalence of human immunodeficiency virus, hepatitis $\mathrm{B}$ and $\mathrm{C}$ viruses, and Treponema pallidum infections among blood donors at
Shiyan, Central China BMC Infect Dis. 16: 531. Published online 2016 Oct 1. doi: 10.1186/s12879-016-1845-z.

[24] Roger M. A. M, Rhode J. M, Blumberg N (2016). Haemovigilance of reactions associated with red blood cell transfusion: comparison across 17 countries. Vox Sang. 110 (3): 266-77.

[25] Awofala A. A, Ogundele O. E, (2016). HIV epidemiology in Nigeria. Saudi Journal of Biological Sciences. http://dx.doi.org/10.1016/j.sjbs.2016.03.006. 9 April.

[26] Ajayi B. B, Moses A. E, Ezimah A. C. U, et al (2007). HIV Prevalence among Blood Donors in University of Maiduguri Teaching Hospital, Maiduguri, Nigeria. International Journal of Virology 3 (1): 35-40.

[27] Farhadpour F, Taherkhani R, Tajbakhsh S, et al (2016). Prevalence and Trends of Transmissible Viral Infections among Blood Donors in South of Iran: An Eleven-Year Retrospective Study. PLoS One 11 (6): e0157615. Doi:10:1371/journal pone. 0157615. eCollecton 2016.

[28] Nebie KY, Olinger CM, Kafando E, et al (2007). Lack of knowledge among blood donors in Burkina Faso (West Africa); potential obstacle to transfusion security. Transfus Clin. Biol. 14: 446-52.

[29] Allain J. P, Sarkadie F, Asenso-Mensah K, et al (2009). Relative safety of first-time volunteer and replacement donors in West Africa. Transfusion. 50: 340-3.

[30] Barreto C. C, Sabino E. C, Gonocalez T. T, et al (2005). Prevalence incidence and residual risk of human immunodeficiency virus among community and replacement first-time blood donors in Sao Paulo, Brazil. Transfusion. 45: 1709-14.

[31] Murphy E, Sanchez-Guerrero S. A, Valiente-Banuet L, et al (2010). Demographic characteristics and infectious disease markers in blood in the Mexico-US border region (Abstract). Vox Sang. 99: 2.

[32] Grabarczyk P, Kopacz A, Sulkowska E, et al (2015). Blood donors screening for blood born viruses in Poland. Przegl Epidemiol. 69 (3): 473-7, 591-5.

[33] Offergeld R, Ritter S, Hamouda O (2012). [HIV, HCV, HBV and syphilis surveillance among blood donors in Germany 2008-2010] Bundesgesundheitsblatt Gesundheitsforschung Gesundheitsschutz. 55: 907-13.

[34] Mora N, Adams WH, Kliethermes S, et al (2016). A Synthesis of Hepatitis C prevalence estimates in Sub-Saharan Africa: 2000-2013. BMC Infect Dis. Jun 13; 16: 283. doi: 10.1186/s12879-016-1584-1.

[35] Daw MA, Shabash A, El-Bouzedi A, et al (2016). Libyan Study Group of Hepatitis and HIV. Modelling the prevalence of hepatitis $\mathrm{C}$ virus amongst blood donors in Libya: An investigation of providing a preventive strategy. World J Virol. 5 (1): 14-22.

[36] Sheikh MY, Atla PR, Ameer A, et al (2013). Seroprevalence of Hepatitis B and C Infections among Healthy Volunteer Blood Donors in the Central California Valley. Gut and Liver, 7 (1): 66-73.

[37] Glynn S. A, Kleinman S. H, Schreiber G. B, et al (2000). Trends in incidence and prevalence of major transfusiontransmissible viral infections in US blood donors, 1991 to 1996. Retrovirus Epidemiology Donor Study (REDS). JAMA. 284 (2): 229-35. 
[38] Kim M. J, Park Q, Min H. K, et al (2012). Residual risk of transfusion - transmitted infection with human immunodeficiency virus, hepatitis $\mathrm{C}$ virus, and hepatitis $\mathrm{B}$ virus in Korea from 2000 through 2010. BMC Infectious Diseases 12:160 http://www.biomedcentral.com/1471$2334 / 12 / 160$.

[39] Adegoke A. O, Akanni O, Dirisu J (2011). Risk of transfusion-transmitted syphilis in a tertiary hospital in Nigeria. N Am J Med Sci. 3 (2): 78-81.

[40] Chikwem J, Mohammed I, Okara G, et al (1997). Prevalence of transmissible blood infections among blood donors at the University of Maiduguri Teaching Hospital, Maiduguri, Nigeria. East Afr Med J. 74 (4): 213-16.

[41] Birhaneselassie M (2016). Prevalence of TransfusionTransmissible Infections in Donors to an Ethiopian Blood Bank Between 2009 and 2013 and Donation Factors That
Would Improve the Safety of the Blood Supply in Underdeveloped Countries. Lab Med. 47 (2): 134-9.

[42] Keshvari M, Sharafi H, Alavian S. M, et al (2015). Prevalence and trends of transfusion-transmitted infections among blood donors in Tehran, Iran from 2008 to 2013. Transfus Apher Sci. 53 (1): 38-47.

[43] Sultan S, Murad S, Irfan SM, et al (2016). Trends of Venereal Infections among Healthy Blood Donors at Karachi. Arch Iran Med. 19 (3): 192-6.

[44] Bloch E. M, Vermulen M, Murphy E (2012). Blood Transfusion Safety in Africa: A Literature Review of Infectious Disease and Organizational Challenges. Transfus Med. Rev. 26 (2): 164-80.

[45] Owusu-Ofori A. K, Parry C. M, Bates I (2011).Transfusion transmitted syphilis in teaching hospital, Ghana. Emerging Infectious Disease. (Letter) 17 (11): 2080-81. 